\title{
Gavriil Adrianovich Tikhov (1875-1960) a pioneer in astrobiology
}

\author{
Victor Tejfel \\ Fessenkov Astrophysical Institute, Almaty, Kazakhstan \\ email: tejf@hotmail.com
}

\begin{abstract}
Astrobiology emerged as a scientific discipline in Kazakhstan more than half-acentury ago and flourished for many years under the leadership of Gavriil A. Tikhov, the oldest Pulkovian astrophysicist, member of the Academy of Sciences of the KazSSR (ASKSSR), and corresponding member of the Academy of Sciences of the USSR.
\end{abstract}

The background for the founding of this new discipline is the following: in 1941, despite the war, the government supported an expedition to Alma-Ata, organized by astronomers from Moscow and Leningrad, for the purpose of observing the total solar eclipse of 21 September 1941. At the end of the war, not all these astronomers had left Alma-Ata. Even during the war, under the initiative of academician V. G. Fessenkov, plans were carried out for an astrophysical observatory. With support from academician K. I. Satpaev, the Institute of Astronomy and Physics was created within the ASKSSR. Later, in 1950, it was divided in two: the Physical-Technical Institute, and the Astrophysical Institute, which now bears the name of its founder, V. G. Fessenkov. Tikhov also stayed in AlmaAta and continued his own work as a member of the ASKSSR. He was well known as a researcher of Mars, one of the authors of the first Pulkovo Course of Astrophysics, the inventor of several optical devices for astrophysical research, and a tireless observer whose observing logbooks may still serve as a example of carefulness and accuracy.

Before describing the founding of astrobiology by Tikhov, it is worth recalling some facts from his biography and his contributions to the development of domestic astrophysics. He was born in 1875 in a small village near Minsk (Belorussia), the son of a railway employee. After 4 years of training at Moscow University, which he finished in 1897, Tikhov continued his education at the Sorbonne University in Paris. There, he was introduced to the Russian astronomer A.P. Gansky, and to J. Janssen, director of the Meudon Observatory. On his advice, Tikhov, together with French astrophysicists, made a balloon flight to observe the Leonids meteor shower in November 1899. More details about his life and activity may be found in his memoirs (Tikhov 1959), in a book by one of his disciples (Suslov 1980), or in other publications (for example, Eremeeva 1966).

Tikhov devoted his years in Alma-Ata to the question of life outside the Earth. He led the organization of the Sector of Astrobotany in the ASKSSR. Its staff was composed of astronomers, physicists and biologists who investigated the fluorescence of plants in the infrared and a number of other optical features. Along with the astrobotany research, some of the astronomers and post-graduate students carried out spectrophotometric observations of the Moon, planets, comets, asteroids, as well as variable and magnetic stars. Their primary goal was to study the optical properties of plants in various climatic conditions, including those which were thought to exist on Mars and Venus. The basic idea was the possibility for plants to accomodate to severe climatic conditions by changing their spectral reflectivity. The existence of vegetation on Mars was seriously considered at that time because observations over several decades had shown seasonal changes, such 
as variations in the size of the polar caps or in the colouring of the darker areas called "seas". Unlike terrestrial vegetation, however, the spectrum of Martian "seas" did not show the characteristic absorption of chlorophyll. This served as a powerful argument for opponents to the presence of life on Mars. But the spectroscopic study of plants that grow in cold climates had shown that the absorption band of chlorophyll becomes wider. This finding was the basis for Tikhov's assumption that, in very low temperature conditions, chlorophyll absorption could become so wide that it would go undetected within a narrow spectral region. The global spectral reflectivity of Martian plants would then be significantly decreased, and the absorption of solar energy would be higher.

Tikhov was a convinced opponent of geocentrism and believed that life is widespread in the universe, contrary to skeptics who thought terrestrial conditions were unique for the development of living organisms. In the 1940-50s, the possibility of life on Mars was a subject of active discussions among scientists and drew attention from a broad audience of people. At Tikhov's lectures (he never shone away from giving public lectures even in his old age), it was sometimes impossible to find room. There and then, a new scientific discipline was born which Tikhov called "Astrobiology". In 1953, under this title, he published a popular book (Tikhov 1953), while his earlier "Astrobotany" (Tikhov 1949) was published by the ASKSSR. Both of these books were based on research carried out in the Sector of Astrobotany and on earlier articles published by the ASKSSR. Results from his research activity and from that of his disciples are contained in the Proceedings of the Sector of Astrobotany and in selected works (Tikhov 1954-1960).

Although Tikhov lived most of his life before the space era, he witnessed its first achievements (satellites, automatic lunar stations). Soon after his death in 1960, the activity of the Sector of Astrobotany ceased by decision of the ASKSSR. At first, city authorities decided to keep Tikhov's house and observatory, along with its environmental grounds (the "Astrobotany Garden") as historical and cultural momentoes and to place them under state protection. It was even proposed to create an astronomical complex (planetarium, museum, public observatory), an initiative which the municipal government supported. But later, these plans were cancelled despite numerous protests in the press (Tejfel 1984, Gostev 1987, Tejfel 1987, Tulegenova 1987), and both the house and observatory were thoughtlessly torn down, including the "Astrobotany Garden".

Interest in the works of Tikhov was keenly shared by foreign scientists. In this respect, the visit which A.G. Wilson (Lovell Observatory) payed to Tikhov in 1958 is very indicative. Wilson had come especially to Alma-Ata after participating in the IAU General Assembly held in Moscow that year. During his visit, Wilson made the following statement: "America has recognized the merits of Tsiolkovskij too late; we correct this mistake by a recognition of Tikhov's works". Many years later, it is clear to us that this was not simply a diplomatic compliment.

\section{References}

Eremeeva, A. I. 1966, Oustanding astronomers of the world (Moscow: Kniga Publ.), p. 293

Gostev A. 1987, The destroyed memory? Ogni Alatau (25 Aug. 1987)

Suslov, A. K. 1980, Gavriil Adrianovich Tikhov (Leningrad: Nauka Press), p. 120

Tejfel, V. 1984, Stars and memory Ogni Alatau (12 Sept. 1984)

Tejfel, V. 1987, Not over yet Kazakhstanskaya Pravda (1 Jul. 1987)

Tikhov, G. A. 1949, Astrobotany, (Alma-Ata: Acad. Sci. KazSSR), p. 23

Tikhov, G. A. 1953, Astrobiology, (Moscow: Molodaya Gvardiya Publ.), p. 67

Tikhov, G. A. 1954-1960, Basic works in 5 volumes, (Alma-Ata: Acad. Sci. KazSSR)

Tikhov, G. A. 1959, Sixty years at a telescope, (Moscow: Detgiz Publ.), p. 160

Tulegenova, A. 1987, An echo above ruins, Kazakhstanskaya Pravda (11 Jan. 1987) 